\title{
Safety and Efficacy of Fixed Dose Combination of Voglibose, Glimepiride and Metformin in Indian Type 2 Diabetes Mellitus Patients
}

\author{
Arif A. Faruqui \\ 504A, Rizvi Mahal CHS, Waterfield Road, Opp.Bhabha Hospital, Bandra West, Mumbai, 400050, India
}

Copyright $(\mathrm{C} 2016$ by authors, all rights reserved. Authors agree that this article remains permanently open access under the terms of the Creative Commons Attribution License 4.0 International License

\begin{abstract}
Worldwide diabetes mellitus is highly prevalent and economically devastating illness. This study was a post marketing surveillance (PMS), non-randomized, open, non-comparative, mono-centric study. The drug administered was a fixed dose combination of voglibose 0.2 $\mathrm{mg}$; glimepiride $1 / 2 \mathrm{mg}$ and metformin $500 \mathrm{mg}$ sustained release (SR). Fifty type 2 diabetic patients were given fixed dose combination twice daily with major meals for 3 months. Baseline value was recorded for glycated haemoglobin (HbA1c), fasting plasma glucose (FPG) and post prandial blood glucose/hyperglycemia (PPHG) level. There was significant decrease from baseline in HBA1c value $10.6 \pm 1.3$ vs. $6.6 \pm 0.4(\mathrm{P}<0.0001)$, FPG levels $208.33 \mathrm{mg} / \mathrm{dl}$ vs. $118.06(\mathrm{P}<0.0001)$, and PPHG levels $360.14 \mathrm{mg} / \mathrm{dl}$ vs. 168.36, $(\mathrm{P}<0.0001)$ after 3 months of treatment. The combination was found to be effective in controlling both fasting and post prandial glucose level and was well tolerated. Investigator commented that the use of triple drug combination is a good option in the management of type 2 diabetes which controls both fasting as well as post prandial blood glucose and ultimately HbA1c values.
\end{abstract}

Keywords Glycated Haemoglobin, Fasting Plasma Glucose, Post Prandial Hyperglycemia, Post Marketing Surveillance

\section{Introduction}

Diabetes Mellitus (DM) is a complex metabolic disorder characterized by hyperglycemia followed by abnormalities in carbohydrate, fat and protein metabolism producing chronic complications [1]. Worldwide DM is highly prevalent and economically devastating illness. The level of morbidity and mortality due to diabetes and its potential complications are enormous, and pose significant healthcare burdens on both families and society. India, the second most populous country of the world, has been severely affected by the global diabetes epidemic [2]. As per the International Diabetes Federation (2013), approximately 50\% of all people with diabetes live in just three countries: China (98.4 million), India (65.1 million) and the USA (24.4 million) [3]. In India, DM has gained the status of potential pandemic with more than 62 million of patients. The data from the ICMR INDIAB study also highlights that prevalence of DM in urban areas ranged from 10.9 to $14.2 \%$ while in rural areas the range was 3.0 to $8.3 \%$ [4].

The multifactor etiology of DM in India includes genetic and environmental causes including obesity, urban migration, and economic boom and lifestyle changes associated with increased living standards. Poor glycemic control, a factor that has been observed in the Indian diabetic population, is responsible for micro- and macro vascular changes that present with diabetes, and can predispose diabetic patients to other complications [5]. A major problem in the management of type $2 \mathrm{DM}$ is that glycemic control with diet and / or drug treatment declines as the disease progresses [6].

The basic principal of combination therapy is that small doses of two drugs, there is greater efficiency and fewer side effects than with a large dose of either drug used as mono therapy [6]. Ample evidence is available to prove that aggressive glycemic control in type 2 diabetes leads not only to an improvement in symptoms and short term health, but also in long term complications. The landmark UKPDS showed that every reduction of $1 \% \mathrm{HbA} 1 \mathrm{c}$ reduced the risk of all micro vascular and macro vascular chronic complications [7]. Some physicians now advocate the therapy combining three oral agents (sulfonylurea, metformin, alpha-glucosidase inhibitor or sulfonylurea, metformin, thiazolidinedione) in the management of type 2 DM [8].

This study was conducted to evaluate the safety of triple drug combination (i.e. voglibose, metformin and glimepiride) and its impact on Glucose Triad i.e. HBA1c, FPG and PPHG. 


\section{Material and Methods}

This was a non-randomized, open labeled, non-comparative, single-centric, and post marketing surveillance (PMS) study. The Fixed dose combination (FDC) of voglibose $0.2 \mathrm{mg}$; glimepiride $1 / 2 \mathrm{mg}$ and metformin $500 \mathrm{mg}$ sustained release (SR) was administered to type $2 \mathrm{DM}$ patients for 3 months. Informed consent was obtained from the patients $\&$ the post marketing surveillance was in accordance with the clinical principles laid down in declaration of Helsinki. A total of 50 type $2 \mathrm{DM}$ patients were enrolled and completed the treatment. At the time of entry into the study, base-line data (including patient demographics, age, sex, body weight) were recorded. Patients were observed on 1st month of treatment, then subsequently at 2 nd and $3 \mathrm{rd}$ month of the treatment.

The patients were asked for the determination of fasting plasma glucose (FPG) and postprandial hyperglycemia (PPHG) regularly at the interval of each month. The glycated hemoglobin (HbA1c) levels were also examined before treatment (at baseline) and after 3 months of treatment. The HBA1c determination was carried out by using BIORAD Micromat II HbAlc instrument. The determination of blood glucose concentration was done by Glucose Oxidase-Peroxidase (GOD-POD) method.

\subsection{Inclusion Criteria}

Patients with age more than 36 yrs, of either sex (male and female), HbAlc $>7 \%$, FPG level $>200 \mathrm{mg} / \mathrm{dl}$ and PPHG $>240 \mathrm{mg} / \mathrm{dl}$ were included in the study. Patients receiving combination treatment of glimepiride and metformin and has not obtained satisfactory control of glucose levels i.e. HBA1c > 7 and FPG > $200 \mathrm{mg} / \mathrm{dl}$ were also included in this trial. Clinical criteria for the evaluation included FPG level, PPHG level, and HbA1c value.

After informed consent was obtained, patients were prescribed to receive the FDC of voglibose $0.2 \mathrm{mg}$; glimepiride $1 / 2 \mathrm{mg}$ and metformin $500 \mathrm{mg}$ SR tablet once daily for three months.

\subsection{Exclusion Criteria}

Patients with current insulin therapy or received insulin for more than six weeks in last 3 months, who had known hypersensitivity to biguanides and sulphonylurea, who are on chronic medication known to affect glucose metabolism were excluded from the study. Also the patients with renal disease or renal dysfunction, with congestive heart failure, hepatic insufficiency, alcoholic person and pregnant and lactating women were excluded from the study.

\subsection{Efficacy and Safety Evaluations}

The primary efficacy variable was the change in HbAlc from baseline to 3 month. Secondary efficacy outcomes included changes in FPG and 2-hour PPHG levels from baseline to the subsequent month of the treatment up to 3 month. Safety outcomes included adverse events, particularly hypoglycemic symptoms. The patients were interviewed and asked for any type of adverse events throughout the study. The patients were specially asked for the hypoglycemic symptoms. The daytime hypoglycemic episodes are usually recognized by sweating, nervousness, tremor, and hunger while night time hypoglycaemia may be without symptoms or manifest as night sweats, unpleasant dreams, or early morning headache.

\subsection{Statistical Analysis}

The analysis of HbAlc and fasting and post prandial glucose was carried out by using graph pad prism 6 . Comparison of FPG and PPHG values between the baseline with the value on the 1 st, 2 nd and 3 rd month of treatment were made, as well as comparison in between these months was done by applying one way analysis of variance $\&$ the Turkeys multiple comparison test. Values of $p<0.05$ were considered statistically significant.

\section{Results}

A total of 50 patients were screened and randomized into the treatment groups and completed the study. The baseline characteristics of all the patients at randomization are summarized in the table 1.

Table 1. Baseline characteristics

\begin{tabular}{|c|c|}
\hline Sex (Male/Female) & $31 / 19$ \\
\hline Age $(\mathrm{yrs})$ & $36-78$ \\
\hline HbA1c $(\%)$ & $10.62 \pm 1.31($ Mean \pm S.D. $)$ \\
\hline FPG $(\mathrm{mg} / \mathrm{dl})$ & $208.30 \pm 29.01($ Mean \pm S.D. $)$ \\
\hline PPHG $(\mathrm{mg} / \mathrm{dl})$ & $360.10 \pm 68.18($ Mean \pm S.D. $)$ \\
\hline Body weight $(\mathrm{kg})$ & $86.06 \pm 11.60$ (Mean \pm S.D. $)$ \\
\hline
\end{tabular}

\subsection{Evaluation of Glycemic Control}

\subsubsection{Glycated haemoglobin ( $\mathrm{HbA1c})$}

HBA1c value was significantly reduced from the baseline after using the triple combination of voglibose, glimepiride and metformin. During the study there was significant differences found in the value of $\mathrm{HbAlc}$ from the baseline to the value observed after the completion of the treatment, respectively. (10.62 \pm 1.31 vs. $6.62 \pm 0.45, \mathrm{P}<0.0001)$ as shown in the figure 1 . 


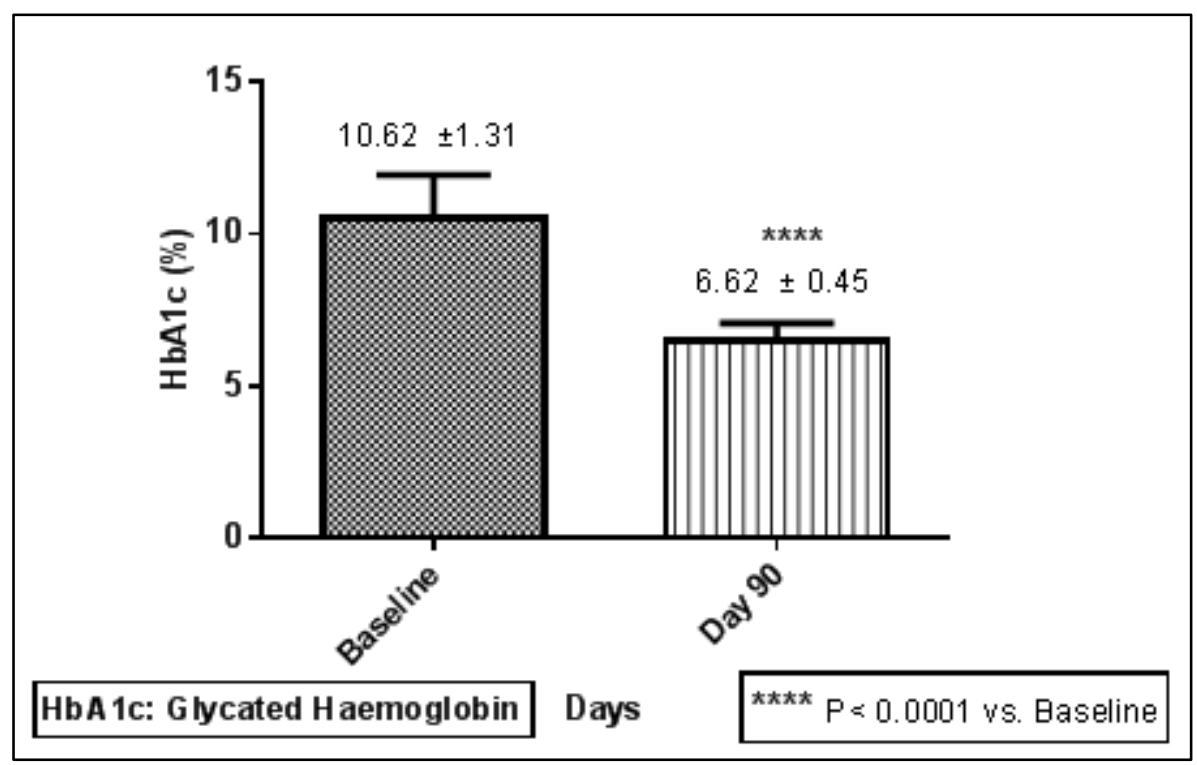

Figure 1. Comparison of Glycated Haemoglobin $(\mathrm{HbAlc})$ from baseline to 3rd month of the treatment (Mean $\pm \mathrm{SD})$

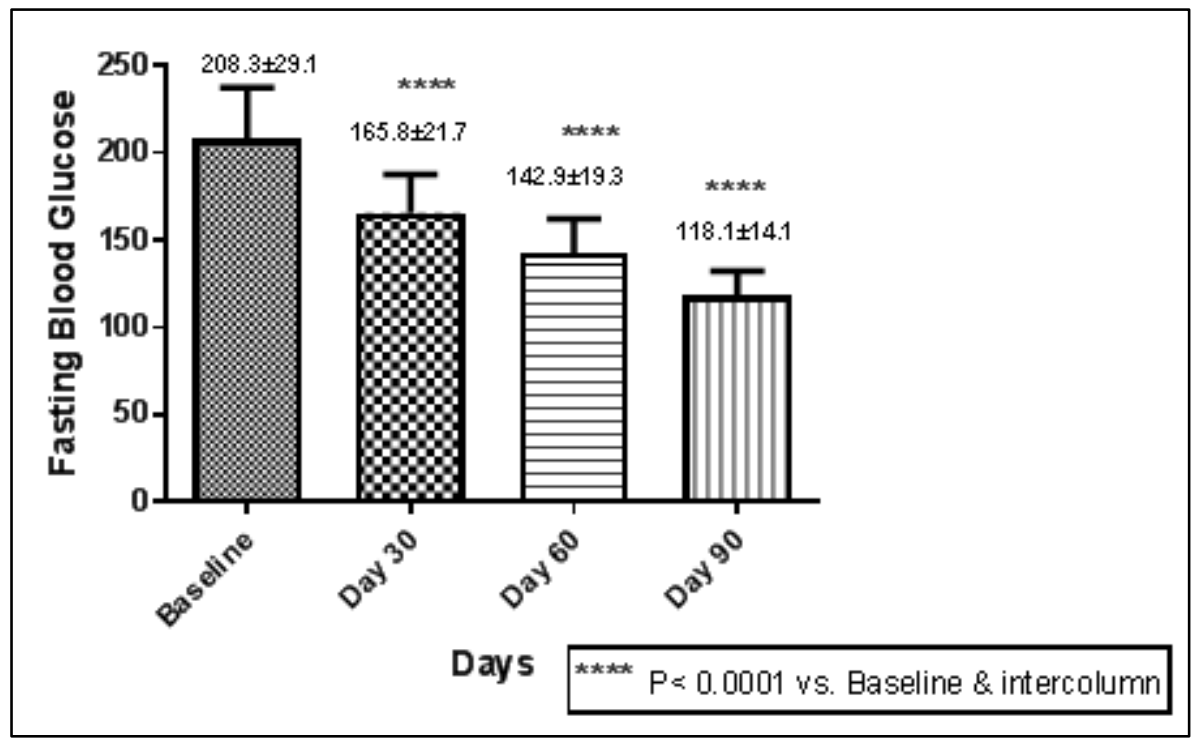

Figure 2. Comparison of Fasting Plasma Glucose (FPG) from baseline to 3rd month of the treatment (Mean \pm SD)

\subsubsection{Evaluation of Fasting Plasma Glucose (FPG) level}

The FPG level was reduced throughout the study period of 3 month. The FPG level was measured at base line and then subsequently at $1 \mathrm{st}, 2 \mathrm{nd}$ and $3 \mathrm{rd}$ month of the treatment. The FPG level was $208.30 \pm 29.01 \mathrm{mg} / \mathrm{dl}$ at baseline. The FPG level was significantly reduced just after 1 month of the treatment from the baseline value $(208.30 \pm 29.01 \mathrm{mg} / \mathrm{dl}$ vs . $165.80 \pm 21.72 \mathrm{mg} / \mathrm{dl}$ ) as well as between the FPG at baseline and at the $3 \mathrm{rd}$ months of the treatment $(208.30 \pm 29.01 \mathrm{mg} / \mathrm{dl}$ vs. $118.10 \pm 14.15 \mathrm{P}<0.0001)$. Overall the FPG level was significantly $(\mathrm{P}<.0001)$ decreased by $90.27 \mathrm{mg} / \mathrm{dl}$ from the baseline after the completion of the study of 90 days. The comparative decrease in FPG level from the baseline to the subsequent month of treatment has been depicted in the figure no. 2.

\subsubsection{Evaluation of Post-Prandial Hyperglycemia (PPHG) level}

The PPHG level was reduced throughout the study period of 3 months. The PPHG level was measured at baseline and then subsequently at 1 st, 2 nd and 3rd month of the treatment. The PPHG level was $360.10 \pm 68.18 \mathrm{mg} / \mathrm{dl}$ at baseline. The PPHG level was significantly reduced on 2 nd month of the treatment vs. baseline $(360.10 \pm 68.18 \mathrm{mg} / \mathrm{dl}$ vs. $196.50 \pm$ $33.57 \mathrm{mg} / \mathrm{dl}$ ) as well as between the PPHG at baseline and to that on the $3 \mathrm{rd}$ month of the treatment $(360.10 \pm 68.18 \mathrm{mg} / \mathrm{dl}$ vs. $168.40 \pm 18.80, \mathrm{P}<0.0001)$. Overall the PPHG level was significantly decreased by $191.76 \mathrm{mg} / \mathrm{dl}$ from the baseline after the completion of the study period of 90 days (Table No. 2). The comparative post PPHG at baseline and the subsequent month of treatment is shown in the figure no.3. 


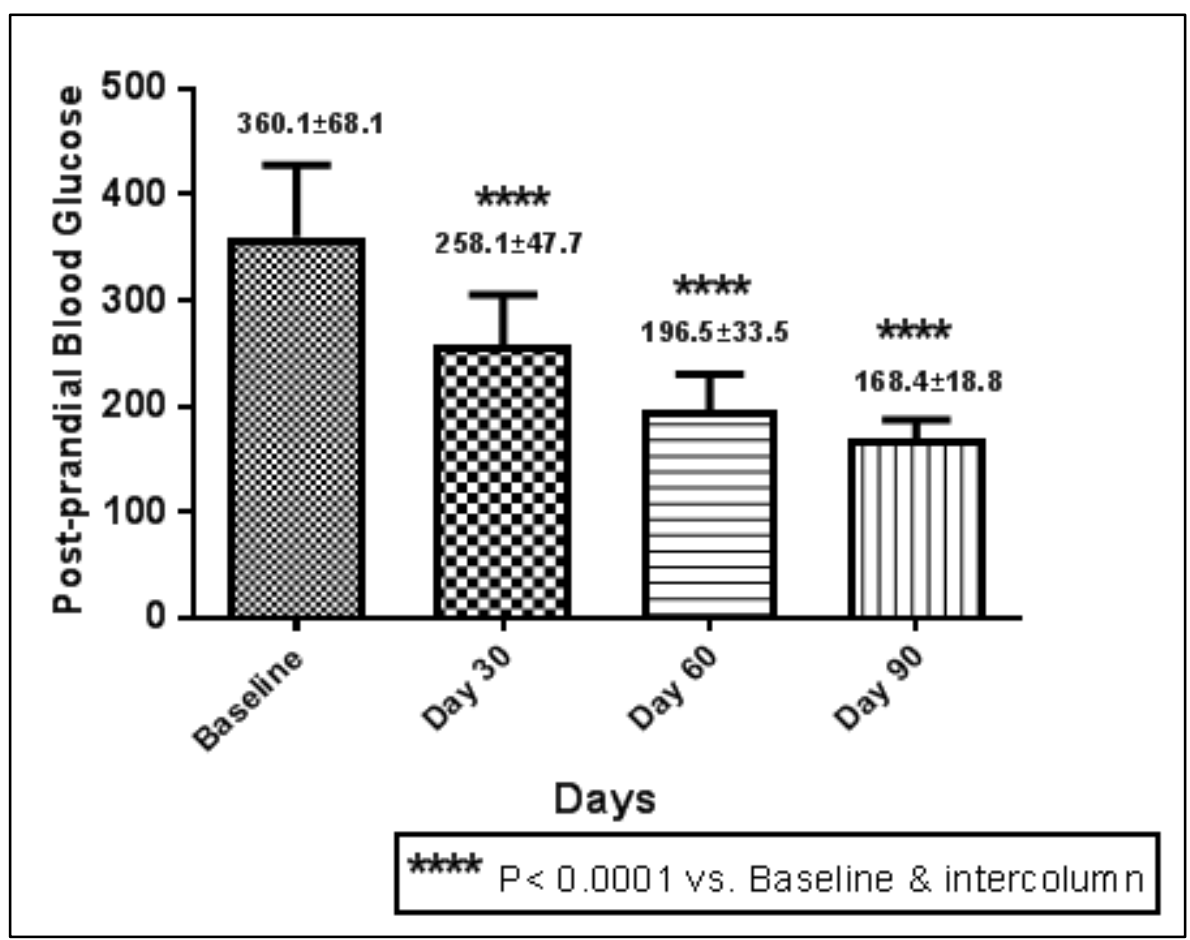

Figure 3. Comparison of PPHG from baseline to 3rd month of the treatment (Mean \pm SD)

Table 2. Evaluation of reduction in FPG, PPHG, HbA1c and body weight variation from the baseline (Mean $\pm \mathrm{SD})$ during the study period (Mean \pm SD)

\begin{tabular}{|c|c|c|c|c|}
\hline Parameters & Baseline & Day 30 & Day 60 & Day 90 \\
\hline FPG (mg/dl) & \multirow{2}{*}{$208.30 \pm 29.01$} & $165.80 \pm 21.72 * * * *$ & $142.90 \pm 19.37 * * * *$ & $118.10 \pm 14.15 * * * *$ \\
\hline$\Delta \mathrm{FPG}(\mathrm{mg} / \mathrm{dl})$ & & -42.55 & -65.47 & -90.25 \\
\hline PPHG(mg/dl) & \multirow{2}{*}{$360.10 \pm 68.18$} & $258.10 \pm 47.71 * * * *$ & $196.50 \pm 33.57 * * * *$ & $168.40 \pm 18.80 * * * *$ \\
\hline$\Delta \mathrm{PPHG}(\mathrm{mg} / \mathrm{dl})$ & & -102 & -163.60 & -191.78 \\
\hline HbAlc (\%) & \multirow{2}{*}{$10.62 \pm 1.31$} & Not applicable & Not applicable & $6.62 \pm 0.45 * * * *$ \\
\hline$\Delta \mathrm{HbA1c}(\%)$ & & Not applicable & Not applicable & -4 \\
\hline Body Weight (kg) & $86.06 \pm 11.60$ & $83.16 \pm 11.46$ & $82.08 \pm 11.13$ & $80.65 \pm 11.03$ \\
\hline
\end{tabular}

$* * * * \mathrm{P}<0.0001$ vs. Baseline \& intercolumn

\subsubsection{Evaluation of body weight variation during the study period}

There were insignificant changes observed in body weight of patients during the whole treatment period. Body weight has been recorded as mean average $( \pm \mathrm{SD})$ at the entry of the study, and then subsequently on 1st, 2nd and on 3rd month of the treatment respectively.

\subsection{Evaluation of Hypoglycemic and Other Adverse Events}

The patients were interviewed throughout the study during each visit as well at the end of the study for the detection of any hypoglycemic episode and about other adverse events like nausea, vomiting and headache. No patient complained about the any significant adverse event including nausea, vomiting, and headache at the given doses of medication.

\subsection{Evaluation of Global Efficacy and Tolerability}

As per investigators assessment about efficacy and tolerability of FDC of Voglibose, Metformin and Glimepiride, $100 \%$ of patients tolerated the treatment and got benefitted. Moreover as regarded by the investigator, FDC of voglibose $0.2 \mathrm{mg}$; glimepiride $1 / 2 \mathrm{mg}$ and metformin $500 \mathrm{mg}$ SR would be the good choice in the management of DM when there is need to control both fasting and PPHG levels.

\section{Discussion}

The management of DM includes diet control, exercise and pharmacological therapy. Post-prandial glucose, similar to post-challenge glucose, was related to cardiovascular disorders (CVD) than fasting glucose. However, higher 
fasting hyperglycemia was not significantly associated with CVD risk [9-11]. Previous analyses suggested that fasting hyperglycemia tended to be associated with beta cell dysfunction, whereas post-challenge hyperglycemia tended to be more strongly related to insulin resistance, higher blood pressure, obesity, and dyslipidemia [12-13].

Choosing medications for people with diabetes involves consideration of a number of factors, including effects on body weight [14]. In the present study patients of DM whose glycemic status was not controlled with two oral hypoglycemic agents (metformin and glimepiride) were given third drug voglibose in the form of FDC. The effect of add on therapy with voglibose as a third agent was observed on various parameters. Among the clinical parameters, there was no significant change observed in body weight of patients at the end of study. While considering single drug treatment, metformin had modest but favorable effects on body weight and mitigate the adverse body weight effects of insulin [15-16], whereas sulfonylureas have been associated with weight gain, whether given as monotherapy or in combination with other classes of oral agents [14]. In this study, the effect of change in body weight was not observed. The plausible explanation for this observed effect is may be due to nullification or cancellation of each drugs effect on body weight by co-administering the other drug in FDC, i.e. the potential of weight gain with sulfonylureas may be neutralized by the weight loss properties of metformin and voglibose [15]. This finding was in accordance with the previous study conducted by Jindal et al [17].

For the optimal management of type 2 DM there is the requirement to understand the relationships between $\mathrm{HbAlc}$, FPG and PPHG level (the glucose triad), and how these change takes place during development and progression of the disease [18]. Early and sustained control of glycemia remains important in the management of type $2 \mathrm{DM}$. When antidiabetic therapy is initiated, physicians may need to consider selection of agents that target both fasting and postprandial hyperglycemia.

M. John et al [19], in a review article reported that, triple FDCs provide effective glycemic control in a safe, well tolerated, and economic manner. They also stated that, the components of FDC acts by different mechanisms thereby targeting multiple pathophysiological targets [19]. Similar results were also reported by $\mathrm{C}$ Rao et al [20], concluding their findings as triple drug combination of voglibose, metformin and glimepiride reduces $\mathrm{HbAlc}$, FPG and PPHG level in type 2 DM patients. C Rao et al in the same study reported that, the above mentioned triple drug FDC was safe and well tolerated in their clinical trial [20]. Dr. Jindal et al [17] in another trial studied the effect of addition of voglibose to the combination of glimepiride and metformin and observed changes on various parameters i.e. FPG, PPHG, HbAlc and lipid profile [Total cholesterol (TC), triglycerides (TG), low density lipoproteins (LDL), very low density lipoproteins (VLDL), high density lipoproteins (HDL)] in type 2 DM patients. At the end of the study it was found that there was a significant reduction in FPG, PPHG and $\mathrm{HbAlc}$ was found with voglibose. The reduction in these parameters was observed in chronological sequence with duration of study i.e. at 1st, 2nd, 3rd, 4th, 5th and 6th months. Addition of voglibose was reported to have an influence on serum lipids. i.e. TC, TG, LDL and VLDL and these were reduced significantly with voglibose [17]. Derosa et al [21] also observed significant reduction in FPG, PPHG and $\mathrm{HbA1c}$ with combination of sulfonylurea, metformin and acarbose.

In this PMS, HbAlc value was significantly reduced from the baseline after using the FDC of voglibose, glimepiride and metformin. During the study there was significant differences found in the value of $\mathrm{HbAlc}$ at the baseline to the value observed after the completion of the treatment $(10.62 \pm 1.312$ vs. $6.622 \pm 0.4510, \mathrm{P}<0.0001)$.

The FPG level was reduced throughout the study period of 3 month. FPG level was significantly $(\mathrm{P}<0.0001)$ decreased by $90.25 \mathrm{mg} / \mathrm{dl}$ from the baseline after the completion of the study of 90 days. Moreover the PPHG level was also reduced throughout the study period of 3 month. Overall the PPHG level was decreased significantly by $191.78 \mathrm{mg} / \mathrm{dl}$ from the baseline after 3 month of treatment.

About the safety profile of this combination, this study reported that no patient was withdrawn from the study due to adverse effects suggesting the excellent safety and tolerability of this combination. Furthermore, this finding is in accordance with the previous study conducted by $\mathrm{C}$ Rao et al [20]. Overall this combination is highly effective and safe in controlling all the glycemic parameters like HbAlc, FPG and PPHG for optimal management of type 2 DM. Regarding the tolerability and safety of the FDC of voglibose $0.2 \mathrm{mg}$; glimepiride $1 / 2 \mathrm{mg}$ and metformin $500 \mathrm{mg} \mathrm{SR}, 100 \%$ of patients tolerated the treatment well without the need for discontinuing the therapy due to adverse events.

\section{Conclusions}

Used wisely, with adequate medication counseling, triple FDC of voglibose $0.2 \mathrm{mg}$; glimepiride $1 / 2 \mathrm{mg}$ and metformin $500 \mathrm{mg}$ sustained release (SR) provides effective glycemic control in a safe and well tolerated manner. This FDC thus provides a valuable option for the management of hyperglycemia.

\section{Conflict of Interest}

All authors had access to the data and vouch for the veracity and completeness of the data and the data analysis. Authors have declared that no competing interests exist.

\section{Acknowledgements}

Author acknowledges the support of Dr. Naresh Arya M.D 
(Medicine), Consulting Physician, Bhopal, for providing the pre and post therapy documentary evidence in diabetic patients. Author also acknowledges the immense help received from the scholars whose articles are cited and included in references of this manuscript. Writing support was provided by Mr. Shailesh Pallewar (M. Pharm. Pharmacology) \&Mr. Altamash Momin (M. Pharm. Pharmacology) provided the statistical analysis.

\section{REFERENCES}

[1] American Diabetes Association Diagnosis and Classification of Diabetes Mellitus Diabetes Care, Vol 32(Suppl 1): S62S67, Jan 2009.

[2] Seema A Kaveeshwar, Jon Cornwall. The current state of diabetes mellitus in India, Australasian Medical Journal, Vol 7, No. 1, 45-48, 2014.

[3] International Diabetes Federation. IDF Diabetes Atlas, $6^{\text {th }}$ edn. Brussels, Belgium: International Diabetes Federation, 2013.

[4] Anjana RM. Prevalence of diabetes and prediabetes in urban and rural India: phase I results of the Indian Council of Medical Research-INdia DIABetes (ICMR-INDIAB) study, Diabetologia, Vol 54, No.12, 3022-7, 2011 Dec.

[5] Unnikrishnan RI, Rema M, Pradeepa R, Deepa M, Shanthirani CS, Deepa R, Mohan V. Prevalence and risk factors of diabetic nephropathy in an urban South Indian population: the Chennai Urban Rural Epidemiology Study (CURES 45), Diabetes Care, Vol 30, No. 8, 2019-24, Aug 2007.

[6] Sovindra K Bharti, Avantika Srivastava, Ranjeet Singh. Review on effect of combination drug therapy on diabetes mellitus and its management, Indian Journal of Research in Pharmacy and Biotechnology, Vol 2, No. 1, 958-964, Jan-Feb 2014

[7] UK Prospective Diabetes Study Group. UK Prospective Diabetes Study 16 (Overview of 6 years' therapy of type II diabetes: a progressive disease), Diabetes, Vol 44, No. 11, 1249-1258, 1995.

[8] Ovalle F, Bell DSH. Triple oral antidiabetic therapy in type 2 diabetes mellitus, Endocrine Practice, Vol 4, No. 3, 146-7, May-Jun 1998.

[9] Glucose tolerance and mortality: comparison of WHO and American Diabetic Association diagnostic criteria, The Lancet, Vol. 354, No. 9179, 617 - 621, Aug 1999.

[10] DECODE Study Group, the European Diabetes Epidemiology Group. Glucose tolerance and cardiovascular mortality: comparison of fasting and 2-hour diagnostic criteria, Archives of internal medicine, Vol 161, No. 3, 397405, Feb 2001.
[11] F. Cavalot, A. Petrelli, M. Traversa, K. Bonomo, E. Fiora, M. Conti. Postprandial blood glucose is a stronger predictor of cardiovascular events than fasting blood glucose in type 2 diabetes mellitus, particularly in women: lessons from the San Luigi Gonzaga Diabetes Study. J. Clin. Endocrinol. Metab. 91 (2006) 813-819.

[12] Kuo-Liong Chien a,b, Bai-Chin Lee b, Hung-Ju Lin b, Hsiu-Ching Hsu b, Ming-Fong Chen. Association of fasting and post-prandial hyperglycemia on the risk of cardiovascular and all-cause death among non-diabetic Chinese, Diabetes research and clinical practice, Vol 83, No. 2, e4 7- e50, Feb 2009.

[13] S. Yamagishi, K. Nakamura, M. Takeuchi. Inhibition of postprandial hyperglycaemia by acarbose is a promising therapeutic strategy for the treatment of patients with the metabolic syndrome, Medical Hypotheses, Vol 65, No. 1, 152-154, Jan 2005.

[14] Priscilla Hollander. Anti-Diabetes and Anti-Obesity Medications: Effects on Weight in People With Diabetes, Diabetes Spectrum, Vol 20, No. 3, 159-165, Jul 2007.

[15] Jack A. Yanovski, Jonathan Krakoff, Christine G. Salaita, Jennifer R. McDuffie, Merel Kozlosky, Nancy G. Sebring, James C. Reynolds, 4 Sheila M. Brady, Karim A. Cali, Diabetes. Vol 60, No. 2, 477-485, Feb2011.

[16] Golay A. Metformin and body weight, International Journal of Obesity (London), Vol 32, No.1, 61-72, Jan 2008.

[17] Amita Jindal, Mahesh Jindal, Mandeep Kaur, Mr. Raj Kumar, Mr. Rajender Singh Brar. Efficacy and safety of voglibose as an add-on triple drug in patients of type two diabetes mellitus uncontrolled with glimepiride and metformin in Punjabi population, Indian Journal of Basic and Applied Medical Research, Vol. 3, No. 3, 111-116, June 2014.

[18] A. Ceriello. The glucose triad and its role in comprehensive glycaemic control: current status, future management, International Journal of Clinical Practice, Vol 64, No.12, 1705-1711, Nov 2010.

[19] Mathew John, Deepa Gopinath, and Sanjay Kalra. Triple fixed drug combinations in type 2 diabetes, Indian Journal of Endocrinology and Metabolism, Vol 19, No. 3, 311-313, May-Jun 2015.

[20] C Rao, A. A. Faruqui. Efficacy and safety of oral triple drug combination (voglibose, glimepiride and metformin) in the management of type 2 diabetes mellitus, International Journal of Current Research and Review, Vol 05, No. 16, 20-26, Aug 2013.

[21] Derosa G, Salvedeo S, Angelo A, Ferrari I, Moreu R, Palumbo I. Metabolic effect of repaglinide or acarbose when added to a double oral antidiabetic treatment with sulphonylureas and metformin: a double blind, cross over, clinical trial, Informa Healthcare, Vol 25, No.3, 607-615, Mar 2009. 